\title{
CD44 is highly expressed on milk neutrophils in bovine mastitis and plays a role in their adhesion to matrix and mammary epithelium
}

\author{
Erez Gonen ${ }^{1,2}$, Shlomo NedvetZKI $^{2}$, David NAOR ${ }^{2}$, Nahum Y. ShPIGEL $^{1 *}$ \\ ${ }^{1}$ The Koret School of Veterinary Medicine, Faculty of Agriculture, POB 12, Rehovot 76100, Israel \\ 2 The Lautenberg Center for General and Tumor Immunology, Faculty of Medicine, POB 12272, \\ Jerusalem 91120, Israel
}

(Received 6 August 2007; accepted 19 December 2007)

\begin{abstract}
Mastitis, inflammation of the mammary gland, is a common and economically important disease in dairy animals. Mammary pathogenic organisms, such as Escherichia coli, invade the teat canal, milk ducts, and mammary alveolar space, replicate in mammary secretions, and elicit a local inflammatory response characterized by massive recruitment of blood polymorphonuclear neutrophil leukocytes (PMN) into the alveoli and milk ducts. CD44 is a trans-membrane glycoprotein previously shown to play a role in mediation and control of blood PMN recruitment in response to inflammatory signals. Here we show, for the first time, increased expression of CD44 on recruited milk PMN in bovine mastitis and the expression of a CD44 variant, CD44v10, on these PMN. Furthermore, we demonstrate that CD44 mediates specific adhesion of bovine blood PMN to hyaluronic acid and mammary epithelial cells. Our results suggest that in mastitis CD44 plays a role in recruiting blood PMN into the mammary glands, the exact nature of this role needs to be elucidated.
\end{abstract}

mastitis / CD44 / neutrophils

\section{INTRODUCTION}

Mastitis, inflammation of the mammary gland, is a common and economically important disease in dairy cattle. Mammary pathogenic organisms contaminating the teat skin and orifice invade the teat canal, milk ducts, and mammary alveolar space, replicate in mammary secretions, and elicit an innate immune response. The interaction of these organisms with mammary alveolar and ductal epithelial cells and/or residential alveolar macrophages elicits a local inflammatory response characterized by massive recruitment of blood polymorphonuclear neutrophil leukocytes (PMN) into the alveoli and milk ducts $[1,12]$. Blood PMN are recruited across

\footnotetext{
*Corresponding author: shpigeln@agri.huji.ac.il
}

chemokine gradients released by mammary cells in response to microbial-associated molecular structures. PMN traffic across the vascular epithelium into the extracellular matrix (ECM) of the interstitial space and across the alveolar epithelium. This complex process is initiated by blood PMN rolling, tethering, and adhering to endothelial cells, followed by extravasation. This cascade of events is dependent on the expression of cell-adhesion molecules such as selectins, integrins, and their counter-receptors or ligands on these cells [2]. Recently, CD44 was identified as one of the three endothelial-selectin (E-selectin) ligands on PMN responsible for slowing down and activating rolling PMN [6]. CD44, in concert with the other two E-selectin ligands (ESL-1 and PSGL-1), were required (but not essential) for PMN extravasation during 
inflammation. There is, however, sparse information on the underlying mechanisms governing PMN trafficking through the mammary ECM and alveolar epithelium into the milk spaces [16]. The ECM and epithelial basement membrane of the mammary gland and other tissues consist of a complex matrix of mucopolysaccharides produced by various interstitial cells and the alveolar epithelium $[7,17]$. These mucopolysaccharides or glycosaminoglycans (GAG) include hyaluronic acid (HA), heparan sulphate, and chondroitin sulphate, which are synthesized and secreted by the polarized mammary alveolar epithelium (MAE), both its apical and baso-lateral aspects. The major cell surface receptor of HA and other GAG is CD44, which is required for cell trafficking through the ECM [13].

CD44 represents a large family of transmembrane protein isoforms or variants generated by alternative splicing of transcripts that result in the addition of various stretches of amino acids in the extracellular part of this protein. Expression of splice variants by cells is usually associated with activation and adaptation for specific sites and functions. PMN were shown to express the standard CD44 isoform, CD44s, but not other variant isoforms [14].

Information on the role of CD44 in the pathogenesis of mastitis is limited. Increased expression of CD44 was reported on bovine milk lymphocytes after an intramammary challenge with Streptococcus uberis but not with Serratia marcescens [4]. Genome-wide expression analysis of mammary tissue in LPS-induced murine mastitis revealed the induction of CD44 among several other adhesion molecules including PSGL-1 [21]. The aim of this study was to investigate the role of CD44 expressed on PMN in the pathogenesis of mastitis.

\section{MATERIALS AND METHODS}

\subsection{Cows}

Milk and blood samples were obtained from a total of 60 lactating Israeli Holstein cows with undifferentiated naturally occurring mastitis from three commercial dairy farms. The initial selection of mastitic and normal cows was based on the monthly analysis of individual cow milk somatic cell counts (SCC) performed by the Central Laboratory for Milk Recording of the Israel Cattle Breeders Association (Fossomatic model 360, Foss Electric, Helleroed, Denmark). Cows with SCC higher than 500000 cells $/ \mathrm{mL}$ were considered to be affected by mastitis and inflammed quarters were tested and identified within two days of SCC analysis by the California mastitis test (CMT), grade 3 (high SCC quarters, HSCC). The grades represented four categories: 0 , negative or trace; 1 , weak positive; 2 , distinct positive; and 3 , strong positive [8]. Milk samples were also collected from normal quarters of the same cows and from normal healthy cows with SCC $<200000$ cells $/ \mathrm{mL}$ where CMT was negative (low SCC quarters, LSCC).

\subsection{Isolation of leukocytes from milk}

Quarter foremilk milk samples were aseptically collected by hand-milking into sterile tubes, and were then placed immediately on ice and maintained at $4{ }^{\circ} \mathrm{C}$ until further processing within $4 \mathrm{~h}$. Each sample of $50 \mathrm{~mL}$ was diluted at a 1:1 ratio with phosphate-buffered saline (PBS) and centrifuged at $500 \times g$ at $4{ }^{\circ} \mathrm{C}$ for $20 \mathrm{~min}$. Next, the cream layer was removed and the pelleted cells were resuspended and washed in $40 \mathrm{~mL}$ PBS. This procedure was repeated twice. Washed cells were immediately analyzed by flow cytometry. An aliquot of each sample was stored in $-80^{\circ} \mathrm{C}$ for RNA extraction.

\subsection{Isolation of PMN from blood}

Blood samples were collected by jugular venipuncture into sterile tubes containing EDTA, and kept on ice until processing. For isolation of PMN, $20 \mathrm{~mL}$ of whole blood was diluted with $20 \mathrm{~mL}$ PBS and gently layered on $10 \mathrm{~mL}$ of HISTOPAQUE ${ }^{\circledR}$ - 1119 (SIGMA diagnostics, Rehovot, Israel). Tubes were centrifuged for $30 \mathrm{~min}$ at $400 \times g$ at $4{ }^{\circ} \mathrm{C}$; the upper phase was aspirated and discarded, and the red blood cells were lysed for $1 \mathrm{~min}$ with double volumes of distilled water followed by fast recovery of isotonicity with PBSX10. The remaining PMN were counted for viability by trypan blue exclusion and analyzed by flow cytometry, reverse transcription-polymerase chain reaction (RT-PCR), 
and adhesion inhibition assays. Based on DiffQuik (Merck KGaA, Darmstadt, Germany) stained cytospin preparation, cell suspensions contained $>98 \%$ PMN.

\subsection{Flow cytometry analysis of cells}

Washed cells $\left(\sim 5 \times 10^{6}\right.$ cells/sample $)$ were stained with two different types of anti-pan CD44 (constant epitopes shared by all CD44 isoforms) monoclonal antibodies (mAb), both found to be immunologically cross-reactive with bovine CD44; IM7.8.1 (mAb against a non-polymorphic determinant on mouse pgp-1 glycoprotein, American type culture collection, TIB-235), and Hermes-3 (mAb against human Peyer's patch endothelial cells CD44, American type culture collection, HB-9480). Both $\mathrm{mAb}$ were used in saturating amounts of $5 \mu \mathrm{g} / \mathrm{mL}$. The secondary antibodies used for fluorescent staining were fluorescein isothiocyanate (FITC) labeled - Affinipure F( $\left.a b^{\prime}\right) 2$ Fragment Goat anti-Rat $\operatorname{IgG}(\mathrm{H}+\mathrm{L})$ and FITC-Affinipure $\mathrm{F}\left(\mathrm{ab}^{\prime}\right) 2$ Fragment Goat anti-Mouse IgG $(\mathrm{H}+\mathrm{L})$ (Jackson ImmunoResearch Laboratories, Inc., West Grove, PA, USA), respectively. The anti-mouse cell surface Ig idiotype (Rat, IgG2b) obtained from hybridoma 4D2 was used as an isotype-matched control for the IM7.8.1 mAb [19]. Antibodies were incubated with the cells for $50 \mathrm{~min}$ at $4{ }^{\circ} \mathrm{C}$ in the dark. After incubations with the secondary $\mathrm{Ab}$, cells were washed three times in washing solution (20\% RPMI, 3\% FCS, in PBS), and analyzed by a FACSCalibur flow cytometer using a single-color (BectonDickinson Immunocytometry Systems, San Jose, CA, USA). The excitation wave length was $488 \mathrm{~nm}$, and the emitted fluorescence was measured at 530 to $560 \mathrm{~nm}$. Dot plots were gated for PMN leukocytes as previously described [11]. Cellular physical characteristics such as size and granularity were assayed by forward and side scattering, respectively. Only live cells were gated and the viability of cells was determined by using propidium Iodide at a final concentration of $10 \mu \mathrm{g} / \mathrm{mL}$, followed by gating on the polymorphonuclear cell fraction. Data were analyzed using CellQuest software (Becton Dickinson). The mean fluorescence intensity (MFI) of CD44 was calculated after plotting fluorescence histograms. Data were expressed as relative fluorescence intensity units after subtracting non-specific labeling (4D2 as the isotype-matched control for the IM7.8.1 mAb, and cells incubated with the secondary antibody only as the control for the Hermes 3 staining).

\subsection{Reverse transcription-PCR (RT-PCR)}

Total RNA was extracted from blood and milkderived cell pellets using a SV Total RNA Isolation System (Promega, Madison, WI, USA). The design of PCR primers was based on the sequence of existing CD44 sequences deposited in GenBank ${ }^{\circledR}$ (NCBI).

First-strand DNA synthesis was performed in a $50-\mu \mathrm{L}$ volume using Promega's AMV RT kit, according to the manufacturer's instructions, using bovine exon 19 (5'-TTACACCCCAATCTTCATAT-3') primer. The reaction was incubated for $50 \mathrm{~min}$ at $40^{\circ} \mathrm{C}$, followed by inactivation of the RTase at $70^{\circ} \mathrm{C}$ for $5 \mathrm{~min}$.

PCR reactions were performed on a PTC-100 Programmable Thermal Controller (MJ Research Inc., Waltham, MA, USA) using the Reddymix PCR kit (Abgene House, Epsom, UK) with primers (10 pmol in $50 \mu \mathrm{L}$ total reaction volume) for exon 5 (sense 5'-TTATACCAAGAAAGGCGAATA3') and exon 15 (anti-sense 5'-GTGAGTTGTATAGGATCTTC-3'). First-strand DNA was used as a PCR template ( $1 \mu \mathrm{L}$ per reaction), using the following protocol: initial heating to $95^{\circ} \mathrm{C}$ for 5 min and then 33 cycles of denaturation at $94^{\circ} \mathrm{C}$ for $1 \mathrm{~min}$, primer annealing at $54^{\circ} \mathrm{C}$ for $1 \mathrm{~min}$, and extension at $72^{\circ} \mathrm{C}$ for $1 \mathrm{~min}$. Final extension was at $72{ }^{\circ} \mathrm{C}$ for $10 \mathrm{~min}$, descending to $4{ }^{\circ} \mathrm{C}$. An aliquot of $20 \mu \mathrm{L}$ of PCR product was electrophoresed on $1.5 \%$ agarose gel containing $1 \mu \mathrm{g}$ of Ethidium Bromide per $\mathrm{mL}$. Bands were visualized by UV transillumination and photographed with a Kodak DC260 digital camera (Eastman Kodak, Rochester, NY, USA), followed by extraction, using Gel DNAextraction kit (Amersham Biosciences, Arlington Heights, IL, USA) and nucleotide sequencing (MEGAbace ${ }^{\circledR}$ 1000, MA, USA).

\subsection{Western blot analysis}

Expression of CD44 protein in milk cells was investigated by Western blot analysis. Cells from LSCC and HSCC quarters were collected as described before, and lysed with NP40 buffer. A $50-\mu \mathrm{g}$ quantity of proteins from each sample was electrophoretically separated on a $10 \%$ SDSPolyacrylamide gel (Serva electrophoresis $\mathrm{GmbH}$, 
Heidelberg, Germany). Thereafter, proteins were transferred onto a P-immobilon PVDF membrane (Millipore, Bedford, MA, USA) using an electrotransblot apparatus (Hoefer miniVE, Amersham Biosciences). The membrane was blocked in Trisbuffered saline containing $0.05 \%$ Tween-20 (TBS$\mathrm{T} \mathrm{pH}$ 7.6) with $3 \%$ skim milk powder for $1 \mathrm{~h}$ at $37^{\circ} \mathrm{C}$. Incubation was performed with Hermes$3 \mathrm{mAb}$ at 1:30 dilution in TBS-T with $1 \%$ bovine serum albumin for $1 \mathrm{~h}$ at room temperature (RT). After three washes with TBS-T for 10 min each on a horizontal shaker, the membrane was incubated with the secondary $\mathrm{Ab}$ (Peroxidase-conjugated Goat anti-Mouse IgG, from Jackson laboratories), diluted 1:1000 in TBS-T, for $1 \mathrm{~h}$ at RT. The membrane was then washed six times in TBS-T on a shaker for $8 \mathrm{~min}$ each. Following a reaction with enhanced chemiluminescence (ECL), according to the manufacturer's instructions (Amersham Biosciences), proteins were detected on Kodak Xray film.

\subsection{Neutrophil adhesion inhibition assays}

Inhibition of bovine peripheral PMN adhesion to hyaluronic acid and to bovine primary mammary epithelial cells by anti-CD44 mAb (IM7.8.1) was evaluated as follows. Flat bottomed 96-well plates were covered with high molecular weight HA (from bovine vitreous humor, Sigma H7630), $0.1 \mathrm{mg}$ in $100 \mu \mathrm{L}$ volume per well, and kept at $4{ }^{\circ} \mathrm{C}$ overnight and then washed three times with PBS. PMN suspension of 60000 viable cells in $100 \mu \mathrm{L}$ PBS was incubated at $4{ }^{\circ} \mathrm{C}$ for $1 \mathrm{~h}$ with $5 \mu \mathrm{g}, 0.5 \mu \mathrm{g}$, $0.25 \mu \mathrm{g}$, or $0.1 \mu \mathrm{g}$ of anti-CD44 mAb (IM7.8.1), followed by three washes with fresh PBS. The 4D2 mAb (isotype-matched control for IM7.8.1) was used as a control to exclude Fc-mediated effects. A total of $60000 \mathrm{PMN}$ in $100 \mu \mathrm{L}$ medium (containing RPMI, 10\% FCS, and Pen-Strep) was added to each HA-coated well in identical triplicates, and left for $2 \mathrm{~h}$ in $37^{\circ} \mathrm{C}$, in a humidified, $5 \% \mathrm{CO}_{2}$ atmosphere. After removal of fluids and three PBS washings, $20 \mu \mathrm{L}$ MTS [3-(4,5-dimethylthiazol-2-yl)-5-(3-carboxymethoxyphenyl)2-(4-sulfophenyl)-2H-tetrazolium] (Promega, TB245) was added to the plates. After $8 \mathrm{~h}$ at $37^{\circ} \mathrm{C}$ in a humidified, $5 \% \mathrm{CO}_{2}$ atmosphere, the absorbance at $490 \mathrm{~nm}$ was recorded using a microtiter plate reader. The linearity and validity of the microplate colorimetric MTS assay for enumeration of bovine peripheral blood PMN were assessed in the range of 0 to 100000 cells using a checkerboard method (data not shown).

Primary bovine mammary epithelium (BME) cell culture was prepared as described elsewhere [20] with slight modifications. Briefly, about $200 \mathrm{~g}$ of fresh mammary tissue was obtained within 20 min of slaughter and transported to the lab, in PBS containing penicillin $\mathrm{G}(100 \mu \mathrm{g} / \mathrm{mL})$, streptomycin $(100 \mu \mathrm{g} / \mathrm{mL})$, gentamicin $(100 \mu \mathrm{g} / \mathrm{mL})$, and amphotericin B $(10 \mu \mathrm{g} / \mathrm{mL})$. The tissue was cut into small cubes of $1 \mathrm{~mm}^{3}$, washed five times with RPMI, and placed in digestive medium containing PBS with $0.5 \mathrm{mg} / \mathrm{mL}$ collagenase IV, $0.4 \mathrm{mg} / \mathrm{mL}$ DNAse I (both from Worthington Biochem Corp, Lakewood, NJ, USA), $0.5 \mathrm{mg} / \mathrm{mL}$ hyaluronidase I$\mathrm{S}$ (Sigma), $50 \mu \mathrm{g} / \mathrm{mL}$ gentamicin, and $10 \mu \mathrm{g} / \mathrm{mL}$ amphotericin B. The 3-h digestion took place in an orbital shaker at $37^{\circ} \mathrm{C}, 100 \mathrm{rpm}$. Cells were then filtered through plastic strainers (pore size $0.4 \mathrm{~mm}$ ) and centrifuged for $5 \mathrm{~min}$ at $40 \times \mathrm{g}$. Next, pellets were resuspended in PBS and strained again through $100-\mu \mathrm{m}$ pores. The suspension was centrifuged again, and pellets were resuspended in DMEM/F12 with 5\% FCS and penicillin/streptomycin. The cells were put into tissue culture flasks for $30 \mathrm{~min}$ at $37^{\circ} \mathrm{C}$ to allow the attachment of fibroblasts. The last step was performed three times. Finally, cells were put into six-well tissue culture plates in growth medium containing DMEM/F12, 5\% FCS, ITS supplement $(5 \mu \mathrm{g} / \mathrm{mL}$ insulin, $5 \mu \mathrm{g} / \mathrm{mL}$ transferrin, and $0.005 \mu \mathrm{g} / \mathrm{mL}$ sodium selenite) (all from Invitrogen, Carlsbad, CA, USA), penicillin G $(100 \mu \mathrm{g} / \mathrm{mL})$, streptomycin $(100 \mu \mathrm{g} / \mathrm{mL})$, gentamicin $(50 \mu \mathrm{g} / \mathrm{mL})$, and amphotericin B $(10 \mu \mathrm{g} / \mathrm{mL})$. Cells were maintained under humidified conditions at $37^{\circ} \mathrm{C}$ and $5 \%$ $\mathrm{CO}_{2}$, and while confluent was passaged twice. The cells were checked for purity with pan-cytokeratin $\mathrm{mAb}$ (clone C-11, Sigma F3418) staining and flow cytometry analysis (data not shown).

In the BME adhesion inhibition assay, PMN were enumerated using the myeloperoxidase (MPO) assay [3]. The linearity and validity of the microplate colorimetric tetramethyl benzidine (TMB, Vector Labs., Burlingame, CA, USA) assay for enumeration of bovine peripheral blood PMN were assessed in the range of 0 to $10^{6}$ cells using the checkerboard method (data not shown).

Primary bovine mammary epithelium was grown in six-well tissue culture plates until a confluent monolayer was formed. PMN suspension of $10^{6}$ viable cells in $1000 \mu \mathrm{L}$ PBS was incubated at $4{ }^{\circ} \mathrm{C}$ 
for $1 \mathrm{~h}$ with $50 \mu \mathrm{g}, 5 \mu \mathrm{g}$, or $0.5 \mu \mathrm{g}$ anti-CD44 $\mathrm{mAb}$ (IM7.8.1) followed by three washes with fresh PBS. The 4D2 mAb (isotype-matched control for IM7.8.1) was used as a control. A total of $10^{6}$ viable $\mathrm{PMN}$ in $1000 \mu \mathrm{L}$ medium (containing RPMI, 10\% FCS, and Pen-Strep) were added to each BME-coated well in identical triplicates, and left overnight at $37^{\circ} \mathrm{C}$, in $5 \% \mathrm{CO}_{2}$. Wells were washed three times with PBS and $1 \mathrm{~mL}$ of PBS containing $1 \%$ Triton $\mathrm{X}-100$ was added to each well and left for $30 \mathrm{~min}$ at $4^{\circ} \mathrm{C}$. A sample of $10 \mu \mathrm{L}$ from each well was transferred into a flat bottomed 96-well plate, with $60 \mu \mathrm{L}$ TMB (Vector labs.) and $80 \mu \mathrm{L}$ DDW. After a 4-min incubation in RT, color development (OD) was assayed at a $630-\mathrm{nm}$ wavelength in a microtiter plate reader. Each well was recorded in three replicates.

\subsection{Statistical analysis}

Each experiment was performed in triplicate and repeated two or more times. Comparison of mean fluorescence intensity (MFI) within and among cows was performed using the Student's $t$ test. Comparison of neutrophil adhesion between experimental groups was analyzed by one-way analysis of variance - comparison of means. Statistical analyses were performed using SPSS 10.0.1 (SPSS Inc., Chicago, IL, USA) and $P<$ 0.05 was considered significant.

\section{RESULTS}

\subsection{CD44 expression on polymorphonuclear cells in bovine mastitis}

To verify the CD44 expression on PMN in a HSCC quarter compared with a LSCC one, we subjected the milk-derived cells to flow cytometric analysis, using IM7.8.1, anti-CD44 $\mathrm{mAb}$, which reacts with all CD44 isoforms. Anti-idiotype, isotype-matched 4D2 mAb was used as a control. As shown in Figure 1, expression of CD44 is substantially higher on PMN of the HSCC quarters than on PMN of LSCC quarters, as indicated by an IM7.8.1 shift to the right of the fluorescence intensity. In addition, PMN from blood and milk of LSCC cows express a basal level of CD44, which was similar to the fluorescence intensity levels of the normal quarters of HSCC cows.

\subsection{Expression of CD44 variant isoforms by milk cells in bovine mastitis}

RNA of PMN derived from HSCC quarters and LSCC quarters of the same cows were extracted and analyzed by RT-PCR to determine the type of CD44 splice variants expressed by the cells. Cells isolated from LSCC quarters expressed a single band at approximately $250 \mathrm{bp}$, which corresponds to the transcript of the standard form of CD44 (CD44s) (Fig. 2A). However, cells isolated from the HSCC quarter of the same cow presented additional bands, corresponding to variant isoforms of CD44 (CD44v). Similarly, milk cells isolated from LSCC cows expressed only the CD44s. These results were consistent in 20 different cows sampled in four different experiments. Extraction and sequencing of the top CD44v PCR product (Fig. 2A and C) revealed complete sequence homology to the previously published CD44v10 (exon 14) expressed by the bovine endothelial cell line [10].

This pattern of variant expression was confirmed by Western blot analysis of proteins expressed in milk cells. An immunoblot analysis of milk PMN, isolated from either LSCC cows or quarters, using Hermes 3 anti-CD44 mAb, revealed expression of a single protein at approximately $80 \mathrm{kDa}$, which corresponds to standard CD44 (Fig. 2B). Similar analysis of milk PMN from HSCC quarters revealed the expression of multiple proteins detected with Hermes 3 anti-CD44 $\mathrm{mAb}$, which most probably express variant isoforms of CD44.

\subsection{Effect of anti-CD44 antibodies on PMN adhesion in hyaluronic acid}

Specific adhesions of bovine PMN to HA were gradually reduced in the presence of increasing concentrations of IM7.8.1 antiCD44 mAb, and complete blocking of PMN adhesion molecules to $\mathrm{HA}$ was detected at a concentration of $50 \mu \mathrm{g} / \mathrm{mL}$ (Fig. 3A). Incubation of PMN with medium alone or with 4D2, the isotype-matched control mAb, did not affect their adhesion to HA. 

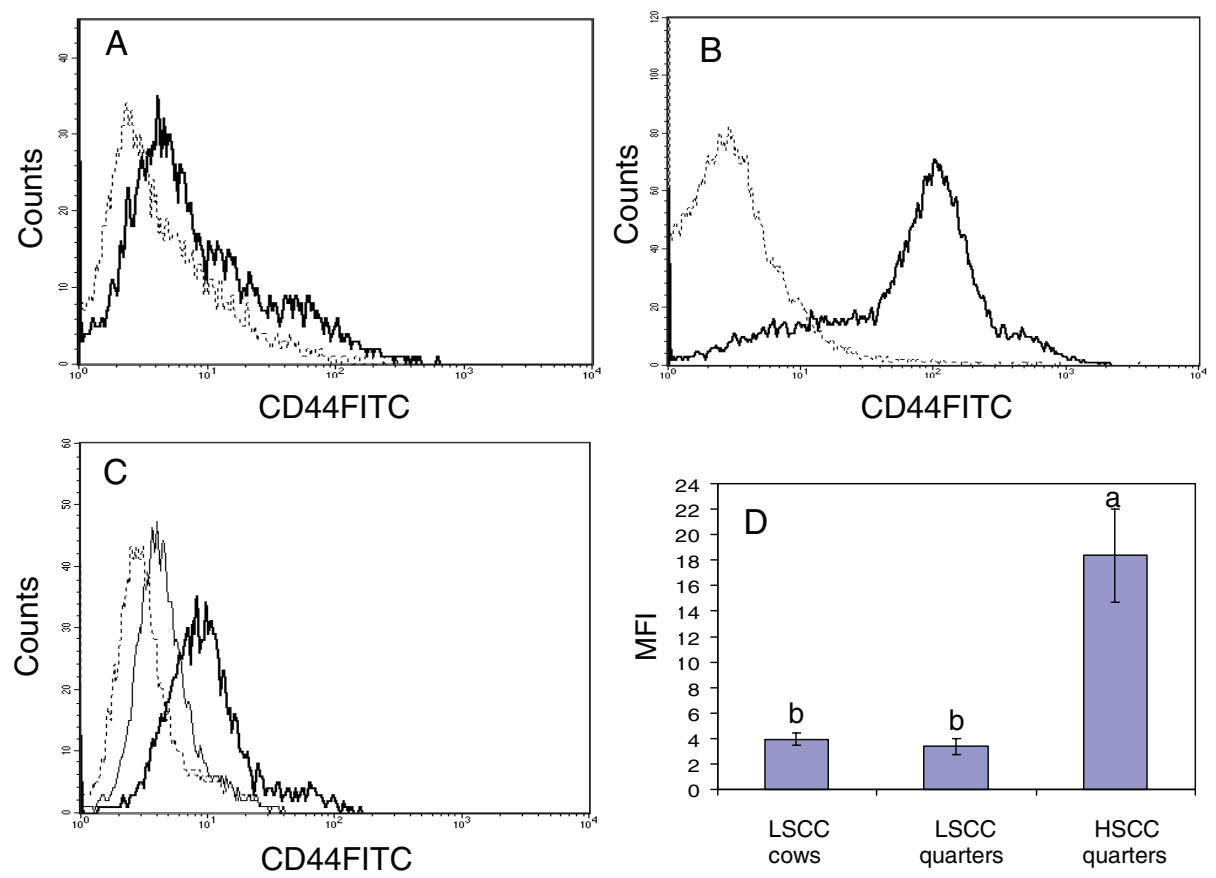

Figure 1. CD44 expression on milk or blood polymorphonuclear cells (PMN) by FACS analysis. Dashed line histograms (event counts versus fluorescence) represent the FACS output for cells stained with background control antibodies. Bold line and thin line histograms denote the FACS output of milk and blood cells, respectively, stained with CD44-specific antibodies (IM7.8.1). Representative pan-CD44 analysis of milk PMN from a LSCC quarter (A), and from a HSCC quarter (B) of the same cow, and of milk and blood PMN from a LSCC cow (C). Summary of mean fluorescence intensity (MFI) of CD44 on milk PMN (D). Data are expressed as mean \pm standard error of 21 LSCC cows and 19 HSCC cows (LSCC quarter and HSCC quarter sample each). Groups with different superscripts differed significantly, $P<0.05$.

\subsection{Effect of anti-CD44 antibodies on PMN adhesion in bovine mammary epithelial (BME) cells}

We found that increasing doses of IM7.8.1 anti-CD44 mAb gradually reduced PMN adhesion to the apical surface of BME cells and complete blocking of the binding was detected at $50 \mu \mathrm{g} / \mathrm{mL}$ (Fig. 3B). Incubation of PMN with medium alone or 4D2, the isotypematched control mAb, did not influence their adhesion to BME cells.

\section{DISCUSSION}

Blood PMN recruitment into the mammary alveolar spaces is the hallmark of host response to bacterial invasion of the mammary milk space [12]. Here we show, for the first time, increased expression of CD44s on recruited milk PMN in bovine mastitis. Furthermore, although PMN are known to express CD44s only, CD44 variants were also expressed on mastitic PMN, one of which was specifically identified as CD44v10. This isoform was previously shown to be expressed on bovine endothelial cells and might play a role in HA-mediated migration of these cells [15]. Furthermore, anti-CD44v10 antibodies specifically affected macrophage recruitment into inflamed skin [22]. In this work we demonstrated adhesion of CD44v10negative blood PMN to HA. This adhesion 

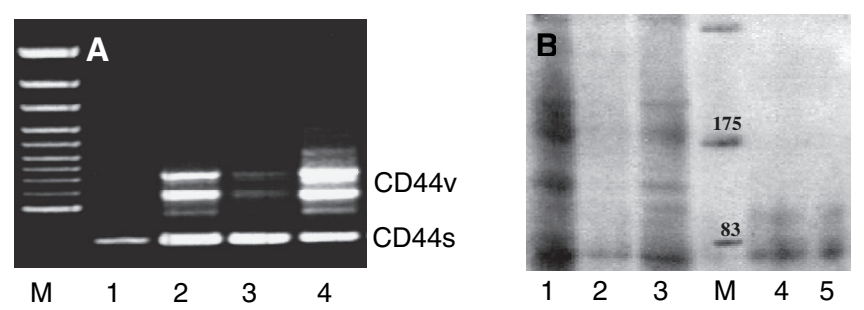

\section{Bovine CD44 v10}

at agg aac gat ggc aga aga ggt gga aat ctt cct gaa gat gca act gct tca atg gaa ggt tac act cat tct cca gac aca aat gaa tac aca acc ctc acc cca gtg acc cct act aag act ggg tcc cct gga gtt act gaa gtt act att gtt gga gat tcc acc tct aag gct gat ctt act tta cca g

Figure 2. RT-PCR (A), Western blot (B) analysis and sequencing (C) of CD44 on milk PMN cells isolated from LSCC and HSCC quarters of cows. Transcripts of standard CD44 (CD44s) are shown in cells from LSCC (A, lanes 1 and 3) and HSCC milk (A, lanes 2 and 4), whereas variant isoforms of CD44 (CD44v) are visible in cells from HSCC quarters only (A, lanes 2 and 4). Western blot analysis of proteins extracted from milk PMN using Hermes $3 \mathrm{mAB}(\mathrm{B})$. PMN cells from LSCC quarters express standard CD44 at approximately $80 \mathrm{Kd}$ (B, lanes 2, 4, and 5), whereas additional variant isoforms of CD44 are expressed by cells from HSCC quarters (B, lanes 1 and 3). Nucleotide sequence of the variable region of a PCR product extracted from the top CD44v band showing complete sequence homology to CD44v10 (C).

was specifically inhibited by anti-pan CD44 (IM7). The role of CD44v10 expression in mammary gland PMN, recruited in response to microbial infection, has not been elucidated, but we suggest that it is involved in recruitment to this organ.

Recruited PMN are also required to traverse the mammary alveolar epithelium, a process that most probably requires adhesion to the basolateral epithelial membrane, opening of interepithelial tight junctions, and adhesion to the apical membrane before detachment into the alveolar milk space. In mice, lactogenic hormones that induce differentiation and milk production down-regulate CD44 expression in mammary epithelial cells [5]. Therefore, mammary epithelial CD44 expression is unlikely to play a role in leukocyte trans-epithelial migration in lactating animals. PMN migration across polarized intestinal epithelium (in either direction) was significantly reduced by preincubation of mouse PMN (but not of epithelial cells) with anti-pan CD44 mAb (IM7) or HA [14].
We show here that bovine PMN adhere to bovine mammary epithelial cells, most probably on the apical side, and that adhesion was specifically inhibited by anti-pan CD44 mAb (IM7).

We have previously shown the importance of LPS-TLR4 signaling in alveolar macrophages in the pathogenesis of experimental LPS and E. coli murine mastitis [3]. In mice, CD44 expressed on hemopoietic cells is an important regulator of LPS-TLR signaling in macrophages, affecting pulmonary inflammatory response and PMN recruitment [9]. However, although intratracheal LPS [9] or intrapulmonary E. coli [18] challenge of $\mathrm{CD} 44^{-1-}$ mice resulted in an exaggerated inflammatory response, none of this was found by us after an intramammary challenge (Gonen E. and Shpigel N.Y., unpublished results). Furthermore, although there is ample evidence for the possible role of CD44 in PMN extravasation, interstitial migration, and trans-epithelial migration, PMN recruitment was unaffected by CD44 deficiency in 

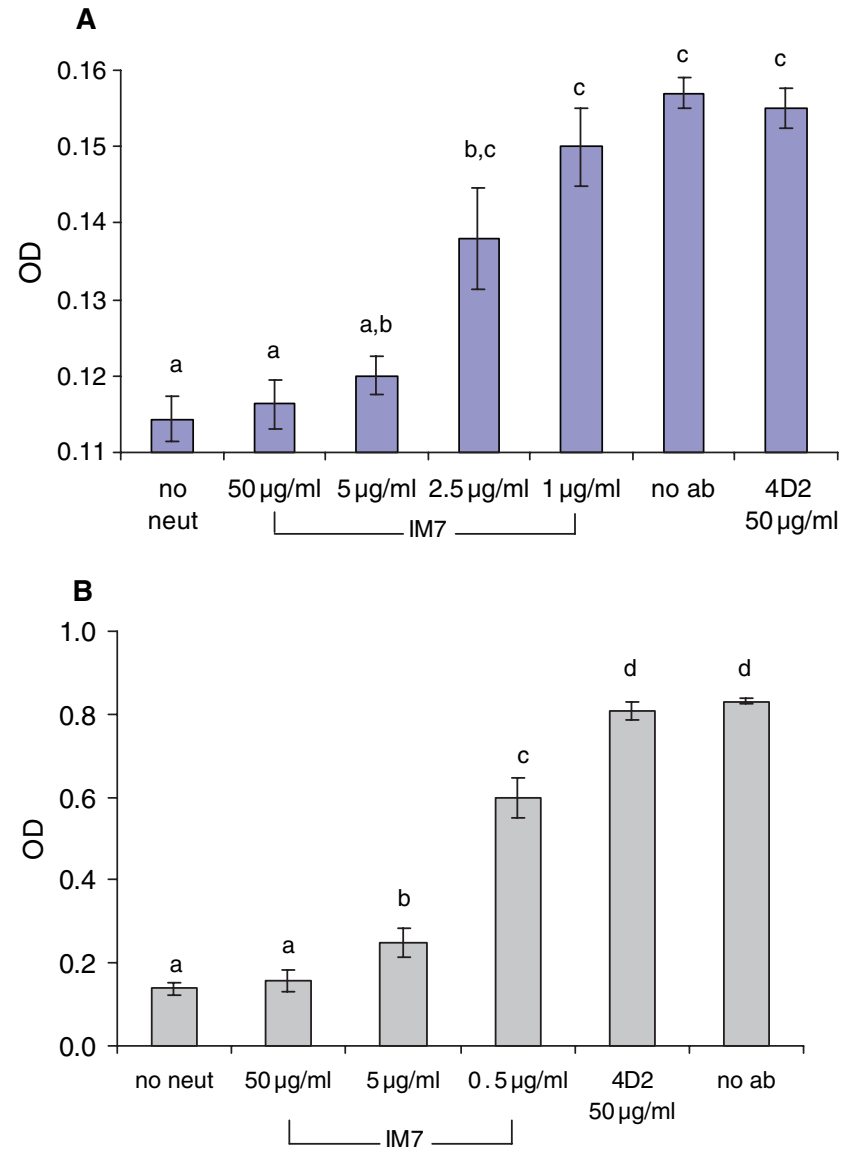

Figure 3. PMN adhesion to hyaluronic acid (HA) and bovine primary mammary epithelial cells (BME) is mediated by CD44. Specific inhibition of bovine peripheral PMN adhesion to HA (top panel) and BME (bottom panel) by anti-CD44 mAb (IM7). The number of adhering PMN was analyzed by microplate colorimetric MTS (HA) or the MPO (BME) assay. Wells without PMN (no neuts), non-treated PMN (no $\mathrm{Ab}$ ), and PMN incubated with the isotype-matched $4 \mathrm{D} 2 \mathrm{mAb}$ were used as controls in both assays. Data represent the mean OD and the bars indicate the standard error (HA) and standard deviation (BME). Groups with different superscripts differed significantly using analysis of variance, $P<0.05$.

the murine mastitis model (Gonen E. and Shpigel N.Y., unpublished results).

In conclusion, our results suggest that in bovine mastitis CD44 plays a role in recruiting blood PMN into the mammary glands, however, the exact nature of this role needs to be elucidated.

Acknowledgments. This study was partially supported by research grant number 668-0034-03 of the Israel Dairy Board.

\section{REFERENCES}

[1] Burvenich C., Van Merris V., Mehrzad J., DiezFraile A., Duchateau L., Severity of E. coli mastitis is mainly determined by cow factors, Vet. Res. (2003) $34: 521-564$

[2] Diez-Fraile A., Meyer E., Burvenich C., Regulation of adhesion molecules on circulating neutrophils during coliform mastitis and their possible immunomodulation with drugs, Vet. Immunol. Immunopathol. (2002) 86:1-10. 
[3] Gonen E., Vallon-Eberhard A., Elazar S., Harmelin A., Brenner O., Rosenshine I., Jung S., Shpigel N.Y., Toll-like receptor 4 is needed to restrict the invasion of Escherichia coli $\mathrm{P} 4$ into mammary gland epithelial cells in a murine model of acute mastitis, Cell Microbiol. (2007) 9:2826-2838.

[4] Harp J.A., Waters T.E., Goff J.P., Bannerman D.D., Paape M.J., Expression of lymphocyte homing and adhesion molecules during intramammary infection of cows with Serratia marcescens or Streptococcus uberis: correlation with bacterial colonization and clinical signs, Vet. Immunol. Immunopathol. (2006) 109:13-21.

[5] Hebbard L., Steffen A., Zawadzki V., Fieber C., Howells N., Moll J., Ponta H., Hofmann M., Sleeman $\mathrm{J} ., \mathrm{CD} 44$ expression and regulation during mammary gland development and function, J. Cell Sci. (2000) 113:2619-2630.

[6] Hidalgo A., Peired A.J., Wild M.K., Vestweber D., Frenette P.S., Complete identification of E-selectin ligands on neutrophils reveals distinct functions of PSGL-1, ESL-1, and CD44, Immunity (2007) 26:477.

[7] Jalkanen M., Rapraeger A., Bernfield M., Mouse mammary epithelial cells produce basement membrane and cell surface heparan sulfate proteoglycans containing distinct core proteins, J. Cell Biol. (1988) 106:953-962.

[8] Kivaria F.M., Noordhuizen J.P., Nielen M., Interpretation of California mastitis test scores using Staphylococcus aureus culture results for screening of subclinical mastitis in low yielding smallholder dairy cows in the Dar es Salaam region of Tanzania, Prev. Vet. Med. (2007) 78:274-285.

[9] Liang J., Jiang D., Griffith J., Yu S., Fan J., Zhao X., Bucala R., Noble P.W., CD44 is a negative regulator of acute pulmonary inflammation and lipopolysaccharide-TLR signaling in mouse macrophages, J. Immunol. (2007) 178:2469-2475.

[10] Lokeshwar V.B., Iida N., Bourguignon L.Y., The cell adhesion molecule, GP116, is a new CD44 variant (ex14/v10) involved in hyaluronic acid binding and endothelial cell proliferation, J. Biol. Chem. (1996) 271:23853-23864.

[11] Monfardini E., Burvenich C., Massart-Leen A.M., Smits E., Paape M.J., Effect of antibiotic induced bacterial clearance in the udder on L-selectin shedding of blood neutrophils in cows with Escherichia coli mastitis, Vet. Immunol. Immunopathol. (1999) 67:373-384.
[12] Paape M.J., Bannerman D.D., Zhao X., Lee J.W., The bovine neutrophil: structure and function in blood and milk, Vet. Res. (2003) 34:597-627.

[13] Ponta H., Sherman L., Herrlich P.A., CD44: from adhesion molecules to signalling regulators, Nat. Rev. Mol. Cell Biol. (2003) 4:33-45.

[14] Si-Tahar M., Sitaraman S., Shibahara T., Madara J.L., Negative regulation of epithelium-neutrophil interactions via activation of CD44, Am. J. Physiol. Cell Physiol. (2001) 280:C423-C432.

[15] Singleton P.A., Bourguignon L.Y., CD44v10 interaction with Rho-kinase (ROK) activates inositol 1,4,5-triphosphate (IP3) receptor-mediated $\mathrm{Ca} 2+$ signaling during hyaluronan (HA)-induced endothelial cell migration, Cell Motil. Cytoskeleton (2002) 53:293-316.

[16] Smits E., Burvenich C., Guidry A.J., MassartLeen A., Adhesion receptor CD11b/CD18 contributes to neutrophil diapedesis across the bovine blood-milk barrier, Vet. Immunol. Immunopathol. (2000) 73:255265.

[17] Sunil N., Srinivasan N., Aruldhas M.M., Govindarajulu P., Impact of oestradiol and progesterone on the glycosaminoglycans and their depolymerizing enzymes of the rat mammary gland, Acta Physiol. Scand. (2000) 168:385-392.

[18] Wang Q., Teder P., Judd N.P., Noble P.W., Doerschuk C.M., CD44 deficiency leads to enhanced neutrophil migration and lung injury in Escherichia coli pneumonia in mice, Am. J. Pathol. (2002) 161:2219-2228.

[19] Weiss L., Slavin S., Reich S., Cohen P., Shuster S., Stern R. et al., Induction of resistance to diabetes in non-obese diabetic mice by targeting CD44 with a specific monoclonal antibody, Proc. Natl. Acad. Sci. USA (2000) 97:285-290.

[20] Wellnitz O., Kerr D.E., Cryopreserved bovine mammary cells to model epithelial response to infection, Vet. Immunol. Immunopathol. (2004) 101:191202.

[21] Zheng J., Watson A.D., Kerr D.E., Genome-wide expression analysis of lipopolysaccharide-induced mastitis in a mouse model, Infect. Immun. (2006) 74:1907-1915.

[22] Zöller M., Gupta P., Marhaba R., Vitacolonna M., Freyschmidt-Paul P., Anti-CD44-mediated blockade of leukocyte migration in skin-associated immune diseases, J. Leukoc. Biol. (2007) 82:57-71. 